\title{
Increasing the intestinal resistance of rats to the invasive pathogen Salmonella enteritidis: additive effects of dietary lactulose and calcium
}

\author{
I M J Bovee-Oudenhoven, D S M L Termont, P J Heidt, $\mathrm{R}$ Van der Meer
}

\begin{abstract}
Background and aims-Lactulose fermentation by the intestinal microflora acidifies the gut contents, resulting in an increased resistance to colonisation by acid sensitive pathogens. The extent of fermentation should be controlled to prevent acid induced epithelial cell damage. Considering the buffering capacity of calcium phosphate and its intestinal cytoprotective effects, whether supplemental calcium phosphate adds to the increased resistance to intestinal infections by lactulose fermentation was studied.

Methods-In a strictly controlled experiment, rats were fed a purified low calcium control diet, a low calcium/lactulose diet, or a high calcium/lactulose diet, and subsequently infected orally with Salmonella enteritidis.
\end{abstract}

Results-Lactulose fermentation lowered the $\mathrm{pH}$ and increased the lactic acid concentration of the intestinal contents, which significantly reduced excretion of this pathogen in faeces; thus it improved the resistance to colonisation. This agreed with the high sensitivity of $S$ enteritidis to lactic acid (main metabolite of lactulose fermentation) in vitro. Calcium phosphate decreased translocation of $S$ enteritidis to the systemic circulation, an effect independent of lactulose. The unfavourable increased cytotoxicity of faecal water caused by lactulose fermentation was more than counteracted by supplemental calcium phosphate. Moreover, calcium phosphate stimulated lactulose fermentation, as judged by the reduced lactulose excretion in faeces and increased lactic acid, ammonia, and faecal nitrogen excretion. Conclusion-Extra calcium phosphate added to a lactulose diet improves the resistance to colonisation and translocation of $S$ enteritidis. This is probably mediated by a calcium induced stimulation of lactulose fermentation by the intestinal microflora and reversion of the lactulose mediated increased luminal cytotoxicity, which reduces damage inflicted on the intestinal mucosa.

(Gut 1997; 40: 497-504)

Keywords: lactulose, calcium, fermentation, infection, resistance, rat.

The disaccharide lactulose (4-O- $\beta-D$-galactopyranosyl- $\alpha-D$-fructofuranose) is a drug mainly used as a laxative and as treatment for portosystemic encephalopathy. ${ }^{1}$ After oral administration, lactulose reaches the lower gut unaltered because it is neither absorbed nor hydrolysed by host digestive enzymes. Although its action is not fully understood, it is supposed to depend on extensive fermentation by the intestinal microflora, resulting in enhanced bacterial growth, acidification of the gut contents because of the production of lactic acid and short chain fatty acids, trapping of ammonia, and stimulation of ammonia incorporation into bacterial protein. ${ }^{2}$ Many Gram negative bacteria such as bacteroides, Escherichia coli, salmonella, and proteus seem to be incapable of degrading lactulose, by contrast with many Gram positive intestinal bacteria, such as lactobacilli and streptococci. ${ }^{3}$ Lactulose therapy has also been used successfully in the management of food borne intestinal infections and inflammatory bowel diseases. ${ }^{4-6}$ Although they are probably one of the prerequisites for the above mentioned beneficial effects of lactulose, the acidic metabolites generated during strong fermentation have to be at least partially neutralised, to prevent damage to the intestinal mucosa. High concentrations of short chain fatty acids (for intance, acetic acid) may induce injury to the colon which is characterised by degeneration and extrusion of enterocytes, increased permeability, and epithelial cell proliferation. ${ }^{7-9}$ Therefore, the extent of intestinal fermentation should certainly be controlled. The aim might be achieved by calcium phosphate supplementation. Dietary calcium phosphate increases the buffering capacity, diminishes the cytotoxic activity of the gut contents, and decreases epithelial cell proliferation. ${ }^{10-12}$ In addition, we previously showed that dietary calcium strongly improves the colonisation resistance to salmonella infection. ${ }^{11}$

The main purpose of the present study was to test the hypothesis that supplemental calcium phosphate adds to the potential beneficial effect of lactulose fermentation on intestinal infections. Therefore, we first performed an in vitro study to compare the bactericidal activity of lactic acid for Salmonella enteritidis and Lactobacillus acidophilus. In addition, the resistance to colonisation and translocation of $S$ enteritidis was studied in a strictly controlled experiment with rats on a purified low calcium control diet, low calcium/ lactulose diet, or high calcium/lactulose diet. $S$ enteritidis was chosen as model pathogen because it is an increasingly important food pathogen ${ }^{13}$ and the course and pathology of a 
salmonella infection resembles that of other common human pathogens, such as campylobacter, Listeria monocytogenes, and some pathogenic Escherichia coli species. ${ }^{14}$

\section{Methods}

BACTERICIDAL ACTIVITY OF LACTIC ACID IN VITRO The bactericidal effect of lactic acid on $S$ enteritidis (clinical isolate, phage type 1 ) and $L$ acidophilus (NIZO B224, collection of our institute) were compared in an in vitro experiment. $S$ enteritidis was cultured and stored as described earlier. ${ }^{15} \mathrm{~L}$ acidophilus was routinely stored at $-80^{\circ} \mathrm{C}$ in sterile skimmed milk containing $0.5 \%(\mathrm{w} / \mathrm{v})$ yeast extract and $20 \%$ (v/v) glycerol. A few days before use, a vial containing the lactobacillus strain was quickly thawed, plated on agar plates according to De Man, Rogosa, and Sharpe (MRS; Merck, Darmstadt, Germany) and incubated overnight at $37^{\circ} \mathrm{C}$ in an anaerobic jar (Anoxomat, Mart bv Microbiology Automation, Lichtenvoorde, The Netherlands). Precultures of $S$ enteritidis and $L$ acidophilus were prepared by inoculating a few colonies from appropriate agar plates in brain heart infusion broth (BHI; Difco, Detroit, MI, USA) and MRS broth (Merck) respectively, followed by overnight aerobic incubation at $37^{\circ} \mathrm{C}$. The next day, bacteria were collected by centrifugation ( 15 minutes at $5000 \mathrm{~g}$ ), washed once, and resuspended in sterile saline to prepare stock suspensions. The bactericidal activity of increasing concentrations of $\mathrm{L}(+)$ lactic acid (Acros Organics, Geel, Belgium) in a citric acid buffer $(50 \mathrm{mM}, \mathrm{pH} 5 \cdot 0$, ionic strength set at $154 \mathrm{mM}$ with sodium chloride, BDH Chemicals Ltd, Poole, England), was tested by inoculating the sterile test medium with the stock suspensions (final $2 \%$ ), followed by a two hour aerobic incubation at $37^{\circ} \mathrm{C}$. Thereafter, several dilutions of the incubates in phosphate buffered saline were plated on brilliant green agar (BGA; Oxoid, Basingstoke, England) and MRS agar (Merck) to determine the viable counts of $S$ enteritidis and $L$ acidophilus, respectively; BGA plates were incubated aerobically for one day and MRS plates were incubated anaerobically for two days. The whole experiment was performed in triplicate.

\section{ANIMALS, DIETS, AND INFECTION}

The experimental protocol was approved by the animal welfare officer of the Agricultural University, Wageningen, The Netherlands. Specific pathogen free male Wistar rats (WU, Harlan, Winkelmann GmbH, Borchen, Germany), eight weeks old and with a mean body weight of about $225 \mathrm{~g}$, were housed individually ( $n=8$ per diet) in metabolic cages in a room with controlled temperature $\left(22-24^{\circ} \mathrm{C}\right)$, relative humidity $(50-60 \%)$, and light/dark cycle (light, 06.00-18.00). During the experimental period of almost three weeks, the animals were fed purified diets. The first group ( $\mathrm{LCa}$ ) received a low calcium control diet $(20 \mathrm{mmol} / \mathrm{kg}$ calcium) consisting of $200 \mathrm{~g}$ acid casein, $502 \mathrm{~g}$ dextrose, $100 \mathrm{~g}$ palm oil, 100 $\mathrm{g}$ corn oil, $50 \mathrm{~g}$ cellulose, $35 \mathrm{~g}$ mineral mix, and $10 \mathrm{~g}$ vitamin mix as described elsewhere, ${ }^{16}$ and $3.44 \mathrm{~g} \mathrm{CaHPO}_{4} .2 \mathrm{H}_{2} \mathrm{O}$ (Merck). The second group ( $\mathrm{LCa} / \mathrm{LACT}$ ) consumed a low calcium diet (calcium $20 \mathrm{mmol} / \mathrm{kg}$ ) supplemented with $10 \%(w / w)$ lactulose (purity 99\%; Solvay Duphar, Weesp, The Netherlands). The third group (HCa/LACT) received a high calcium diet (180 mmol/kg calcium), also supplemented with $10 \%$ (w/w) lactulose. Lactulose and extra calcium phosphate were added at the expense of dextrose. After preparation, samples of the diets were dry ashed for mineral analyses. Calcium and iron were measured with an atomic absorption spectrophotometer (Model 1100, Perkin Elmer Corp, Norwalk, USA). Phosphate was determined spectrophotometrically. ${ }^{17}$ The diets were supplied to the animals as a porridge (double distilled water was mixed with the dry diets to obtain $68 \%$ dry weight). The rats had free access to food and demineralised drinking water. Food intake was recorded every three days and body weight every four days. Before infection, nonfasted blood samples were collected by orbital puncture (after anaesthesia with diethyl ether). Plasma samples were prepared by low speed centrifugation (10 minutes at $1500 \mathrm{~g}$; Eppendorf 5415) of the heparinised blood, and stored at $-20^{\circ} \mathrm{C}$ until analysis. Plasma urea concentrations were determined with a colorimetric kit (Procedure No 640, Sigma Chemical Co, St Louis, USA).

Animals were acclimatised to housing and dietary conditions for 10 days, after which they were orally infected by gastric gavage with $1 \mathrm{ml}$ saline containing $3 \%(\mathrm{w} / \mathrm{v})$ sodium bicarbonate with $S$ enteritidis (same isolate as used in the in vitro experiment). The inoculum contained $4 \times 10^{8} S$ enteritidis per $\mathrm{ml}$, as determined by plating on BGA. The virulence of the strain used is sustained by routine oral passage in Wistar rats, followed by isolation of translocated salmonella from liver or spleen. Before, and on days 1, 5, and 8 after salmonella infection, fresh individual faecal samples were collected. Faeces were thoroughly mixed and homogenised in saline $(1: 3 \mathrm{w} / \mathrm{v})$. Calibrated sterile loops were used to plate the faecal homogenates on Modified BGA (Oxoid) containing the detergent sulphamandelate (Oxoid), to suppress swarming bacteria such as proteus. Applying a rapid bacteriological technique, intoduced and validated by Giaffer et $a l^{18}$ a set of partially overlapping streaks were made on the selective plates. Subsequently, the plates were cultured aerobically for 20 hours at $37^{\circ} \mathrm{C}$.

ANALYSES OF NITRIC OXIDE OXIDATION PRODUCTS (NO $)_{\mathbf{x}}$ IN URINE

Complete 24 hour urine samples were collected for eight days, starting one day before infection. Concentration of $\mathrm{NO}_{\mathbf{x}}$ (nitrate and nitrite) was determined by automated flow injection analysis. Briefly, diluted urine is passed over a cadmium column to reduce nitrate to nitrite, followed by reaction of nitrite 
with Griess reagent. ${ }^{19}$ The red azo dye formed was measured spectrophotometrically at 538 $\mathrm{nm}$. Urinary $\mathrm{NO}_{\mathrm{x}}$ concentration was multiplied by the urine volume produced in 24 hours to obtain daily urinary $\mathrm{NO}_{\mathrm{x}}$ excretion. Recovery of nitrate or nitrite added to rat urines always exceeded $90 \%$.

\section{TOTAL FAECES ANALYSES}

Faeces were quantitatively collected three days before salmonella infection and on days 2,3 , and 4 after infection. Faeces were freeze dried for dry weight determination. For determination of unfermented lactulose, 13 volumes of distilled water were added per mg freeze dried faeces. After homogenisation, samples were heated for five minutes at $95^{\circ} \mathrm{C}$ to denature glycosidases, followed by centrifugation (five minutes at $10000 \mathrm{~g}$, Eppendorf 5415). Supernatants were cleared from hydrophobic substances on octadecyl columns (100 mg; Varian, Harbor City, USA). Water eluates were analysed for lactulose by high performance liquid chromatography (HPLC). ${ }^{20}$ Recoveries of lactulose added to faeces varied between $96 \%$ and $113 \%$. For lactic acid determination, dry faeces were acidified with $1.0 \mathrm{M}$ perchloric acid (1:40 w/v), mixed, and subsequently centrifuged (two minutes at $10000 \mathrm{~g}$; Eppendorf 5415). The supernatant was neutralised to $\mathrm{pH} 7$ by adding $2.0 \mathrm{M}$ potassium bicarbonate $(2: 1 \mathrm{v} / \mathrm{v})$, followed by centrifugation (two minutes at 10000 $g$, Eppendorf 5415). D- and L-lactic acid in the supernatant liquids were separately determined with a colorimetric enzymatic kit (No 1112821, Boehringer Mannheim, Germany). Recoveries of lactic acid added to faeces were $>90 \%$. For ammonia determination, faeces were acidified with $5 \%$ perchloric acid $(1: 20 \mathrm{w} / \mathrm{v})$, incubated for 15 minutes at $37^{\circ} \mathrm{C}$, and centrifuged (two minutes at $14000 \mathrm{~g}$, Eppendorf 5415). The aspirated supernatant was neutralised to $\mathrm{pH} 7$ by adding $3.0 \mathrm{M} \mathrm{KOH}$ in $250 \mathrm{mM}$ 3-N-morpholinopropanesulphonic acid (10:3 $\mathrm{v} / \mathrm{v})$. After mixing, samples were centrifuged (two minutes at $14000 \mathrm{~g}$; Eppendorf 5415). Ammonia in the supernatants was determined using a colorimetric kit originally designed to measure urea (procedure No 640, Sigma Chemical Co). By omitting the first incubation step with urease, ammonia can be determined directly. Recovery of ammonium chloride added to faeces was $>85 \%$. Faecal nitrogen was determined as described elsewhere. ${ }^{21}$ Briefly, faeces were totally acid digested, followed by colorimetric determination of the ammonia formed. Faecal mucins were extracted and determined as described earlier, ${ }^{11}$ with some modifications. Before analysis, interfering pigments were removed from water faecal extracts by filtration (Ultrafree MC NMWL, cut off $30000 \mathrm{Da}$, Millipore, Bedford, USA) during centrifugation (30 minutes at $3000 \mathrm{~g}$ Eppendorf 5415). Subsequently, mucins on the filter membranes were washed once with an equal volume of methanol $(100 \%)$ to remove remaining pigments (centrifugation for another 30 minutes at $3000 \mathrm{~g}$ ). After drying of the membrane inserts by air, the mucin retentate was resolubilised in the original volume of phosphate buffered saline. Mucins were measured using a specific fluorimetric assay. ${ }^{22}$ Standard solutions of $\mathrm{N}$-acetylgalactosamine (Sigma) were used to calculate the amount of oligosaccharide side chains liberated from mucins. Faecal mucins are therefore expressed as $\mu \mathrm{mol}$ oligosaccharide equivalents. Using this procedure, recoveries of porcine stomach mucin (Sigma) added to freeze dried faeces always exceeded $90 \%$. After destruction (15 minutes at $\left.180^{\circ} \mathrm{C}\right)$ with a perchloric acid $(70 \%)$ /hydrogen peroxide $(30 \%)$ mixture $(3: 1 \mathrm{v} / \mathrm{v})$ of freeze dried faeces, calcium, total phosphate, and iron were measured as described for the diets. Inorganic phosphate was extracted from freeze dried faeces with $5 \%(w / v)$ trichloroacetic acid and measured as described above. The amount of organic phosphate in faeces was calculated by subtracting the inorganic phosphate concentration from the total phosphate concentration. In the trichloroacetic acid extracts sodium and potassium were analysed by atomic emission spectrophotometry (Model 1100, Perkin Elmer). Total bile acids were extracted from freeze dried faeces with a $t$-butanol/water mixture $(1: 1 \mathrm{v} / \mathrm{v})$ as described previously. ${ }^{23}$ Extracts were assayed for bile acids using a fluorimetric, enzymatic assay. ${ }^{24}$ Recovery of deoxycholic acid (Sigma) added to faeces always exceeded $90 \%$.

\section{FAECAL WATER ANALYSES}

Faecal water was prepared by reconstituting freeze dried faeces with demineralised water to $30 \%$ dry weight, which reflects the dry weight percentage of colonic contents. ${ }^{10}$ Samples were thoroughly mixed and subsequently incubated (one hour at $37^{\circ} \mathrm{C}$ ) in a shaking water bath. After centrifugation for 20 minutes at 12000 $g$ (Hettich, Micro-rapid 1306, Tuttlingen, Germany), the aspirated supernatant was centrifuged again for two minutes at $14000 \mathrm{~g}$ (Eppendorf 5415). The $\mathrm{pH}$ of the supernatants was measured at $37^{\circ} \mathrm{C}$. Faecal waters were stored at $-20^{\circ} \mathrm{C}$ until further use. The cytotoxic activity was determined with an erythrocyte assay as described previously ${ }^{11}$ and validated elsewhere. ${ }^{25}$ The incubations were of physiological ionic strength $(154 \mathrm{mM})$ and buffered at $\mathrm{pH} 7$ (final $100 \mathrm{mM}$ 3-N-morpholinopropanesulphonic acid; Sigma). After acidification with $\mathrm{HCl}$ (final $1 \mathrm{M}$ ), bile acids were extracted from faecal water three times with diethyl ether. After evaporation of the diethyl ether from the pooled fractions, the residue was resolubilised in methanol. Bile acids in the methanol extracts were quantified using the same method as described for total faeces. Recoveries of a cholic acid/deoxycholic acid (Sigma) mixture, added to faecal waters, varied between $80 \%$ and $120 \%$. Iron was measured in faecal water diluted with distilled water as described for the diets.

\section{STATISTICS}

Results of the in vitro experiment are presented as means (SD) $(n=3)$. Results of the infection 


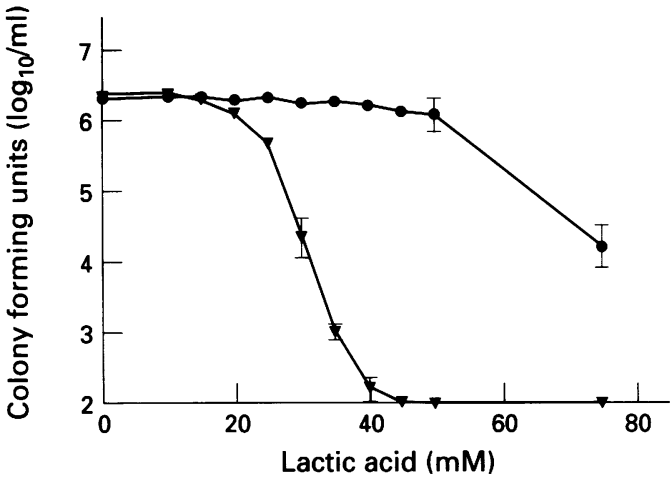

Figure 1: Bactericidal effect of lactic acid on Salmonella enteritidis ( ) and Lactobacillus acidophilus (O) in vitro. Increasing concentrations of lactic acid were added to a citric acid buffer ( $50 \mathrm{mM}, \mathrm{pH} 5 \cdot 0$, physiological ionic strength). After a two hour incubation, survival of the bacteria was determined by plating techniques. Values are means (SD) of triplicate incubations. Where SDs are not shown they are smaller than the size of the symbols.

experiment are presented as means (SEM) $(n=8)$. Within one dietary group, changes induced by infection were tested by Student's $t$ test for paired samples (one sided). Within one period (before and after infection), differences between diet groups were tested for significance by analysis of variance (ANOVA). In addition, Fisher's protected least significant difference test (one sided), modified for multiple comparisons, was used to identify dietary groups that differed from each other. The level of significance was preset at $\mathrm{p}<0 \cdot 05$. A commercially available statistical package was used for all statistics (SPSS/ $P C+$ version $2 \cdot 0$, SPSS Inc, Chicago, USA).

\section{Results}

BACTERICIDAL ACTIVITY OF LACTIC ACID IN VITRO $S$ enteritidis was much more sensitive to the bactericidal activity of lactic acid than $L$ acidophilus (Fig 1). Killing of $S$ enteritidis started at a lactic acid concentration of $20 \mathrm{mM}$ and was complete at $40 \mathrm{mM}$ lactic acid. By contrast, even a concentration as high as $50 \mathrm{mM}$ lactic acid did not affect the viability of $L$ acidophilus. At $75 \mathrm{mM}$ lactic acid, the highest concentration tested, the number of colony forming units was reduced by a factor of 100 only.

ANIMALS, FOOD INTAKE, AND DIARRHOEA MARKERS

All data from one animal in the LCa/LACT group were excluded from the study results

TABLE I Effect of a low calcium (LCa), low calcium/lactulose (LCa/LACT), and high calcium/lactulose (HCa/LACT) diet on faecal output, faecal electrolytes, and mucin excretion before and after oral infection with $\mathrm{S}$ enteritidis

\begin{tabular}{|c|c|c|c|c|}
\hline Variable & Infection & $L C a$ & $L C a / L A C T$ & $H C a / L A C T$ \\
\hline Dry weight (g/day) & $\begin{array}{l}\text { Before } \\
\text { After }\end{array}$ & $\begin{array}{l}0.79(0.03)^{a} \\
0.81(0.04)^{a}\end{array}$ & $\begin{array}{l}0.59(0.14)^{\mathrm{b}} \\
1.01(0.20)^{\mathrm{a} \star}\end{array}$ & $\begin{array}{l}1.39(0.10)^{\mathrm{c}} \\
1.71(0.13)^{\mathrm{b} \star}\end{array}$ \\
\hline Sodium and potassium $(\mu \mathrm{mol} / \mathrm{g})$ & $\begin{array}{l}\text { Before } \\
\text { After }\end{array}$ & $\begin{array}{l}34(3)^{a} \\
75(17)^{2 \star}\end{array}$ & $\begin{array}{l}154(14)^{\mathrm{b}} \\
175(15)^{\mathrm{b} \star}\end{array}$ & $\begin{array}{l}75(7)^{\mathrm{c}} \\
88(11)^{2}\end{array}$ \\
\hline Mucins ( $\mu$ mol equivalents/day) & $\begin{array}{l}\text { Before } \\
\text { After }\end{array}$ & $\begin{array}{l}1.7(0.1)^{\mathrm{a}} \\
5.7(0.7)^{\mathrm{a} \star}\end{array}$ & $\begin{array}{l}31.3(5.7)^{\mathrm{b}} \\
51.7(9.9)^{\mathrm{b} \star}\end{array}$ & $\begin{array}{l}13.6(2.7)^{c} \\
14.3(5.5)^{c}\end{array}$ \\
\hline
\end{tabular}

Values are means (SEM). Values in the same row not sharing the same superscript are significantly different $(p<0.05)$. ${ }^{\star}$ Denotes a significant infection induced change $(p<0.05)$. because of oropharyngeal reflux of the $S$ enteritidis suspension which resulted in pneumonia. At the start of the experiment mean body weight of the rats was $223 \mathrm{~g}$. Weight gain of the LCa/LACT group was significantly less when compared with the other two groups, even before infection. At the end of the experiment (day 8 postinfection) body weights were 281 (7), 250 (7), and 273 (10) $\mathrm{g}$ for the LCa, $\mathrm{LCa} / \mathrm{LACT}$, and $\mathrm{HCa} / \mathrm{LACT}$ groups respectively. During the experiment, the $\mathrm{LCa}$ and $\mathrm{HCa} / \mathrm{LACT}$ groups ate $14.5 \mathrm{~g}$ dry food per day, whereas the LCa/LACT group ate about $3 \mathrm{~g}$ less $(\mathrm{p}<0 \cdot 05)$. Before infection, lactulose increased dry faecal output only in combination with high calcium (Table $\mathrm{I}, \mathrm{p}<0.05$ ). The infection stimulated faecal dry weight excretion in both lactulose groups (Table I, $\mathrm{p}<0.05)$. No proper assessment of faecal wet weight excretion or the dry:wet weight ratio could be made because of drying up of faecal pellets during collection in the metabolic cages (especially for the LCa/LACT group). For that reason, hydration of faeces was determined by the concentration of the electrolytes sodium and potassium. Before infection, the summed concentration of these electrolytes in faeces increased in the order $\mathrm{LCa}<\mathrm{HCa} / \mathrm{LACT}$ $<\mathrm{LCa} / \mathrm{LACT}$ (Table I, all $\mathrm{p}<0 \cdot 05$ ). A significant infection induced increase in faecal electrolyte concentration was found only in the two low calcium groups, by contrast with the calcium supplemented group (Table I). Lactulose supplementation significantly stimulated faecal mucin excretion, which was most pronounced in combination with low calcium (Table I, p<0.05). After infection, faecal mucin excretion increased significantly in both low calcium groups, whereas no infection induced stimulation was found in the $\mathrm{HCa} / \mathrm{LACT}$ group (Table $I, p<0.05$ ). The infection had no defined affect on body weight gain or food intake.

RESISTANCE TO COLONISATION AND

TRANSLOCATION OF SALMONELLA

The rats fed lactulose had a significantly improved colonisation resistance to $S$ enteritidis. The first day after infection of the rats, lactulose feeding reduced faecal $S$ enteritidis excretion about 1000-fold when compared with the low calcium control group (Fig $2, \mathrm{p}<0 \cdot 05$ ). Probably due to large interindividual variation in the response to infection in the lactulose supplemented groups, no significant differences in faecal $S$ enteritidis output were found later in the experiment. Despite comparable faecal $S$ enteritidis excretions of the LCa/LACT and $\mathrm{HCa} / \mathrm{LACT}$ groups, these groups differed greatly in their resistance to translocation of $S$ enteritidis, as measured by urinary $\mathrm{NO}_{\mathrm{x}}$ excretion (Fig 3). Independent of dietary lactulose, both low calcium groups showed a rapid, progressive increase in daily urinary $\mathrm{NO}_{\mathrm{x}}$ output. By contrast, total urinary $\mathrm{NO}_{\mathrm{x}}$ excretion induced by infection (expressed as the area under the $\mathbf{N O}_{\mathbf{x}}$ curve after infection, corrected for baseline $\mathrm{NO}_{\mathrm{x}}$ excretion) of the $\mathrm{HCa}$ LACT group was significantly less $(p<0 \cdot 05)$. 


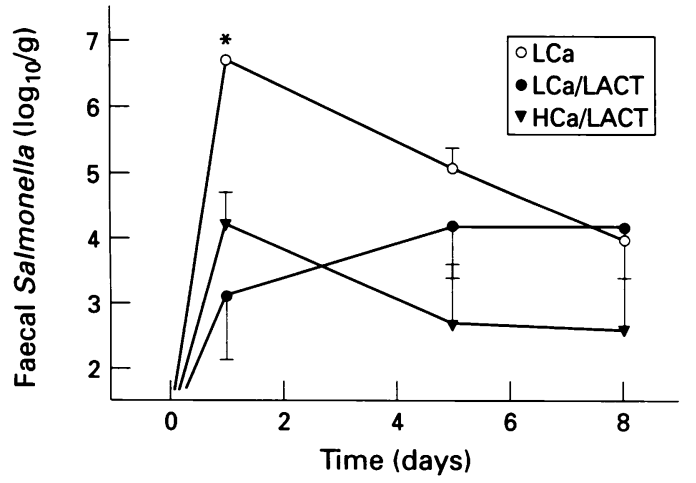

Figure 2: Effect of a low calcium diet (LCa), low calcium/ lactulose diet ( $L C a / L A C T$ ), or high calcium/lactulose diet ( $H C a / L A C T)$ on faecal excretion of $S$ enteritidis after oral administration of $4 \times 10^{8}$ colony forming units of this pathogen to rats on day 0 . Results are expressed as means (SEM) $(n=8)$. SEMs are either smaller than symbols or indicated by bars. ${ }^{\star}$ Denotes that faecal $\mathrm{S}$ enteritidis excretion of the indicated group is significantly different from the other groups $(p<0.05)$.

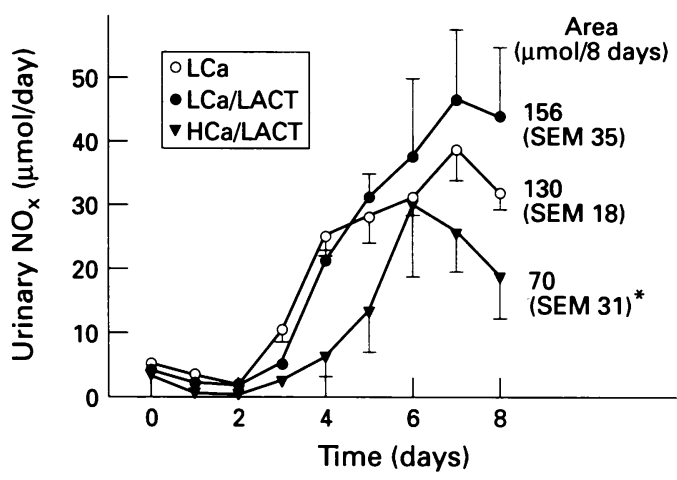

Figure 3: Effect of a low calcium diet ( $L C a)$, low calcium/ lactulose diet (LCa/LACT), or high calcium/lactulose diet (HCa/LACT) on the kinetics of urinary $N O_{x}$ excretion of rats before and after an oral challenge with $4 \times 10^{8} \mathrm{~S}$ enteritidis on day 0 . In addition, the area under the $\mathrm{NO}_{x}$ time curve after infection is presented. Results are expressed as means (SEM) $(n=8)$. ${ }^{\star}$ Denotes that the infection induced $N O_{x}$ excretion of the indicated group is significantly different from the other groups $(p<0.05)$.
CYTOTOXICITY AND COMPOSITION OF FAECAI

WATER

Dietary lactulose strongly reduced the $\mathrm{pH}$ of faecal water (Fig 4A). Faecal water of the $\mathrm{HCa} /$ LACT group was more acidic than that of the LCa/LACT group (Fig 4A, p<0.05). Considering the low $\mathrm{pH}$ of the faecal waters, the cytotoxicity assay was performed in a buffered (pH 7) system. Compared with the low calcium control group, lactulose significantly increased the cytotoxic activity of faecal water. This adverse effect of lactulose was counteracted by supplemental calcium. In fact, faecal water of the $\mathrm{HCa} / \mathrm{LACT}$ group had the lowest cytotoxic activity (Fig 4B, p<0.05). Lactulose did not significantly affect the concentration of bile acids in faecal water, whereas calcium decreased the concentration of these surfactants (Fig 4C, p<0.05). Lactulose greatly increased the solubility of iron in faeces, an effect which was reversed by dietary calcium (Fig 4D, p<0.05). The infection did not significantly affect the cytotoxicity, $\mathrm{pH}$, or iron concentration of faecal water. Only in the LCa group was a significant increase in the bile acid concentration of faecal water induced by infection found $(+0.59 \mathrm{mM})$.

\section{COMPOSITION OF TOTAL FAECES}

Lactulose decreased daily faecal excretion of calcium and inorganic phosphate when combined with low calcium (Table II, $\mathrm{p}<0 \cdot 05$ ). As expected, daily faecal output of these minerals was substantially higher in the $\mathrm{HCa} / \mathrm{LACT}$ group $(p<0.05)$. Fermentation of lactulose by the intestinal microflora was more complete in the high calcium group. Daily lactulose excretion in faeces was $3.9 \mu \mathrm{mol}$ in the $\mathrm{HCa} /$ LACT group, whereas the LCa/LACT group excreted more than 20 times as much (Table II, $\mathrm{p}<0.05)$. Daily faecal excretion of lactic

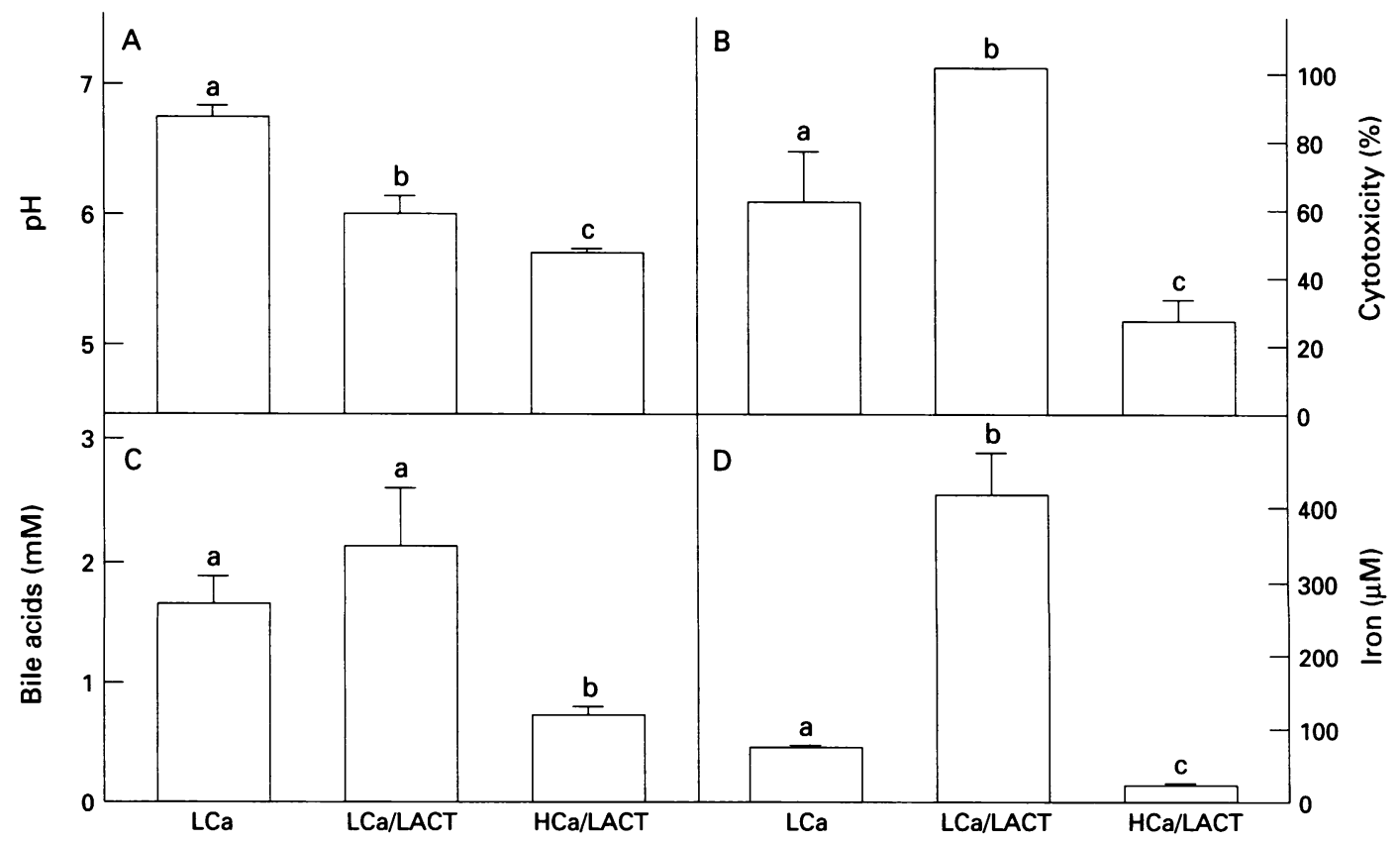

Figure 4: Effect of a low calcium diet (LCa), low calcium/lactulose diet (LCa/LACT), or high calcium/lactulose diet (HCa/LACT) on the $p H$ of faecal water $(A)$, cytotoxicity $(B)$, bile acid concentration $(C)$, and iron concentration (D) of faecal water before infection. Results are expressed as means $(S E M)(n=8)$. Bars not sharing the same letter are significantly different $(p<0 \cdot 05)$. 
TABLE II Effect of a low calcium ( $L C a$ ), low calcium/lactulose ( $L C a / L A C T$ ), and high calcium/lactulose (HCa/LACT) diet on several faecal excretion variables before infection

\begin{tabular}{|c|c|c|c|}
\hline Faecal excretion & $L C a$ & $L C a / L A C T$ & $H C a / L A C T$ \\
\hline $\begin{array}{l}\text { Calcium ( } \mu \mathrm{mol} / \text { day) } \\
\text { Inorganic phosphate ( } \mu \mathrm{mol} / \text { day) } \\
\text { Lactulose ( } \mu \mathrm{mol} / \text { day) } \\
\text { Lactic acid ( } \mu \mathrm{mol} / \text { day) } \\
\text { Ammonia ( } \mu \mathrm{mol} / \text { day) } \\
\text { Nitrogen (mmol/day) } \\
\text { Organic phosphate ( } \mu \mathrm{mol} / \text { day) } \\
\text { Bile acids ( } \mu \mathrm{mol} / \text { day) }\end{array}$ & $\begin{array}{c}53 \cdot 2(6 \cdot 2)^{\mathrm{a}} \\
30 \cdot 2(2 \cdot 3)^{\mathrm{a}} \\
0^{\mathrm{a}} \\
1 \cdot 6(0 \cdot 5)^{\mathrm{a}} \\
15 \cdot 9(1 \cdot 6)^{\mathrm{a}} \\
0 \cdot 90(0 \cdot 04)^{\mathrm{a}} \\
32 \cdot 3(1 \cdot 4)^{\mathrm{a}} \\
15 \cdot 1(1 \cdot 1)^{\mathrm{a}}\end{array}$ & $\begin{array}{l}9 \cdot 6(2 \cdot 5)^{\mathrm{b}} \\
10 \cdot 9(2 \cdot 9)^{\mathrm{b}} \\
90 \cdot 8(35 \cdot 3)^{\mathrm{b}} \\
26 \cdot 3(12 \cdot 8)^{\mathrm{b}} \\
39 \cdot 5(13 \cdot 2)^{\mathrm{b}} \\
1.39(0 \cdot 28)^{\mathrm{b}} \\
30 \cdot 6(6 \cdot 9)^{\mathrm{a}} \\
7 \cdot 7(1 \cdot 5)^{\mathrm{b}}\end{array}$ & $\begin{array}{l}1363(105)^{\mathrm{c}} \\
650(44)^{\mathrm{c}} \\
3 \cdot 9(0 \cdot 7)^{\mathrm{c}} \\
122(21)^{\mathrm{c}} \\
70 \cdot 5(8 \cdot 7)^{\mathrm{c}} \\
2 \cdot 69(0 \cdot 22)^{\mathrm{c}} \\
145(15)^{\mathrm{b}} \\
14 \cdot 3(1 \cdot 3)^{\mathrm{a}}\end{array}$ \\
\hline
\end{tabular}

Values are means (SEM). Values in the same row not sharing the same superscript are significantly different $(\mathrm{p}<0 \cdot 05)$

acid, a product of lactulose fermentation, was strongly increased by supplemental calcium (Table II, $\mathrm{p}<0.05$ ). The contribution of D-lactic acid to total lactic acid excretion was $0 \%, 9 \%$, and $37 \%$ for the $\mathrm{LCa}, \mathrm{LCa} / \mathrm{LACT}$, and $\mathrm{HCa} / \mathrm{LACT}$ groups respectively. Lactulose consumption increased faecal ammonia, which was further stimulated by supplemental calcium (Table II, p<0.05). The lactulose induced stimulation of faecal nitrogen excretion was notably increased by supplemental calcium (Table II, $\mathrm{p}<0 \cdot 05$ ). The contribution of ammonia to total faecal nitrogen excretion did not exceed $3 \%$ in any group. The $\mathrm{HCa} / \mathrm{LACT}$ group had an increased excretion of organic phosphate in faeces (Table II, $\mathrm{p}<0.05)$. In combination with low calcium, lactulose decreased faecal bile acid excretion (Table II, p<0.05).

PLASMA UREA CONCENTRATION

Before infection, lactulose consumption significantly decreased plasma urea concentrations $(p<0.05)$. Plasma urea concentrations were $4.49(0.25), 3.38(0.24)$, and $3.11(0.25) \mathrm{mM}$ for the LCa, LCa/LACT, and $\mathrm{HCa} / \mathrm{LACT}$ groups respectively.

\section{Discussion}

The present study clearly shows that dietary calcium phosphate substantially adds to the beneficial effect of supplemental lactulose on the resistance to $S$ enteritidis. Lactulose greatly enhanced the resistance to colonisation of $S$ enteritidis. The first day after infection of the rats, faecal excretion of viable $S$ enteritidis was reduced more than 1000 -fold when a lactulose diet was consumed (Fig 2). An important product of lactulose fermentation in the rat (Table II) and human ${ }^{326}$ intestine is lactic acid, which seemed to be strongly bactericidal for $S$ enteritidis (Fig 1). Notwithstanding the improvement in colonisation resistance, lactulose did not affect translocation of $S$ enteritidis, as measured by the kinetics of urinary $\mathrm{NO}_{\mathrm{x}}$ excretion (Fig 3). We have previously shown that urinary excretion of oxidation products of nitric oxide (nitrite and nitrate) is a sensitive biomarker to quantify bacterial translocation across the gut wall. ${ }^{15} \mathrm{~A}$ major advantage is that by contrast with tissue cultures, urinary $\mathrm{NO}_{\mathrm{x}}$ excretion reflects the systemic pathogen load of the host. On intestinal bacterial translocation and the subsequent systemic infection, nitric oxide is produced by many infected cells - for instance, macrophages, Kupffer cells, and neutrophils. ${ }^{27}$ Moreover, tissue cultures do not estimate the total bacterial translocation because this method only counts the still viable bacteria and not the large majority of translocated bacteria that are killed after invasion. ${ }^{28}$ The initial site of $S$ enteritidis translocation seems to be the ileal Peyer's patches. ${ }^{29}$ Particularly, the specialised antigen sampling $M$ cells are exploited by this invasive pathogen to gain access to host tissues. ${ }^{30}$ Fermentation of lactulose by the endogenous microflora, resulting in acidification of the intestinal contents (Fig 4A), is thought to be the basis for the therapeutic effect of this disaccharide on intestinal infections. ${ }^{3}$ Considering that most of the endogenous microflora resides in the lower gut (caecum and colon), whereas the small intestine is relatively sparsely populated, ${ }^{31}$ it is not directly feasible that translocation processes can be influenced by lactulose. Indeed, the $\mathrm{pH}$ lowering effect of lactulose fermentation in the human ${ }^{2}$ and rat $^{32}$ ileum is limited: the $\mathrm{pH}$ of the soluble phase of ileal contents drops from 7.5 to 7.0 after lactulose supplementation. Although the small intestine does not have the luxuriant bacterial flora of the colon, lactobacilli are predominant species in this region of the gastrointestinal tract. ${ }^{33}$ Several investigations have shown that these bacteria exert an antagonistic action towards food borne pathogens (for review, see Mital and $\mathrm{Garg}^{33}$ ), including $S$ enteritidis. ${ }^{34}$ Moreover, the lactobacilli are capable of fermenting lactulose ${ }^{35}$ and are rather insensitive to the lactic acid formed, certainly when compared with the salmonella species used in this study (Fig 1). If, in the present study, a growth advantage by lactulose supplementation was achieved for these lactic acid bacteria in the ileum, it was apparently not enough to improve the competition with and resistance to translocation of $S$ enteritidis. By contrast with the lack of protection of lactulose against translocation of $S$ enteritidis, the present study clearly shows that supplemental calcium phosphate is capable of diminishing translocation (Fig 3). Thus whereas the appreciated activity of lactulose is limited to the lower gut, calcium phosphate already exerts protection in the small intestine, reducing the severity of the systemic infection. That the $\mathrm{HCa} / \mathrm{LACT}$ group had the best resistance to $S$ enteritidis infection, was supported by the absence of significant infection induced increases in faecal sodium and potassium concentrations and mucin excretion (Table I), which are diarrhoea markers. ${ }^{36} 37$ In both low calcium groups (with or without lactulose), faecal mucin output and the concentration of faecal electrolytes increased significantly after infection. Before infection, lactulose supplementation increased the faecal electrolyte concentration, the effect being most pronounced in combination with a low calcium diet. Similar effects of lactulose on faecal sodium and potassium concentrations, in addition to softening of stools, have been reported in human studies. ${ }^{38} 39$

The lactulose fermentation mediated increased colonisation resistance to $S$ enteritidis in 
this study, might also be relevant for resistance to other pathogenic bacteria. During lactulose therapy, the $\mathrm{pH}$ of human proximal colonic contents drops below $5 .^{2}$ With the exception of shigella, ${ }^{40}$ common human pathogens such as campylobacter, Escherichia coli, and Vibrio cholerae share their acid sensitivity with $S$ enteritidis. All these pathogens are largely killed in the acid stomach, considering that the viable oral inoculum necessary to cause intestinal disease in humans is very high $\left(>10^{7}\right) .^{14}$

A mechanism which might account for the improvement of the barrier function of the intestinal mucosa induced by dietary calcium is the formation of an amorphous calcium phosphate complex in the small intestine, which precipitates cytotoxic bile acids and fatty acids, thereby reducing epithelial cell damage. ${ }^{12}{ }^{41}$ In the present study, the cytotoxicity of faecal water was highest in the LCa/LACT group, intermediate in the LCa group and lowest in the $\mathrm{HCa} / \mathrm{LACT}$ group (Fig $4 \mathrm{~B}, \mathrm{p}<0.05$ ). Considering the fall in the $\mathrm{pH}$ of faecal water induced by lactulose fermentation (Fig 4A), the cytotoxicity assay was performed in a buffer of neutral $\mathrm{pH}$, precluding simple acid induced lysis. Excluding a direct effect on the low $\mathrm{pH}$ by these precautions, lactulose obviously increased the cytotoxicity of faecal water in combination with a low calcium diet. This unfavourable stimulation of the cell damaging activity of intestinal contents by lactulose fermentation was more than reversed by supplemental calcium phosphate. In accordance with its lowest cytotoxicity, faecal water of the $\mathrm{HCa}$ / LACT group also has the lowest concentration of cytotoxic bile acids (Fig $4 \mathrm{C}, \mathrm{p}<0.05$ ). In the $\mathrm{LCa} / \mathrm{LACT}$ group, the combination of a high bile acid concentration in faecal water and an enhanced protonation and absorption of these surfactants resulted in a decreased daily faecal excretion of bile acids (Table II). When luminal calcium phosphate was limited, fermentation of lactulose greatly increased the intestinal solubility of iron (Fig 4D). Remarkably, coprecipitation of iron by calcium phosphate ${ }^{11}$ was absolutely not counteracted by the acidic colonic environment. To minimise epithelial cell damage and to maximise the barrier function of the mucosa, the solubility of iron in the intestinal lumen should be low because iron is a catalyst in Fenton-like reactions, resulting in lipid peroxidation and depletion of antioxidant defences. ${ }^{42}$ The increased luminal cytotoxicity and potential iron mediated peroxidative damage during extensive intestinal fermentation might account for the compensatory mucosal hyperproliferation in several studies. ${ }^{79}$ Although most of the daily consumed dose of lactulose was metabolised by the intestinal flora, a significantly more complete fermentation was achieved on a high calcium diet when compared with the low calcium diet (Table II). This agrees with the results of Rémésy et $a l^{9}$ showing a more intensive fermentation of inulin on a high calcium diet. As the $\mathrm{pH}$ of faecal water of the $\mathrm{HCa} / \mathrm{LACT}$ group was more acidic than that of the LCa/LACT group (Fig 4A, p<0.05), the increased intestinal buffering capacity, introduced by calcium phosphate, obviously facilitates fermentation until acidity finally stagnates bacterial growth. In the present study, lactulose increased faecal output of ammonia and nitrogen (Table II, $\mathrm{p}<0.05)$. This agrees with results obtained in other rat $^{43}$ and human studies. ${ }^{24}$ Besides lactulose, stimulation of faecal nitrogen output can also be achieved by consumption of other fermentable substrates such as gum arabic (human study), ${ }^{45}$ resistant starch, ${ }^{46}$ or lactitol ${ }^{43}$ (rat studies). In the present study, supplementation of the diets with calcium phosphate significantly enhanced the lactulose induced increase in faecal ammonia and nitrogen, as well as organic phosphate excretion (Table II). Faecal nitrogen ${ }^{43} 47$ and organic phosphate can be regarded as markers of bacterial mass. To benefit optimally from the increased fermentable substrate delivery to the lower gut, as is intended with lactulose supplementation, an adequate supply of calcium phosphate seems to be essential to stimulate the intestinal microflora. So, in addition to the intestinal acid production, the occupation of adhesion sites on the epithelium, the competition for nutrients, and the production of antimicrobials might have been increased by the extended resident flora and also have contributed to the improved resistance to $S$ enteritidis. ${ }^{48}$ The decrease in plasma urea concentration in the lactulose supplemented groups $(p<0.05)$ might indicate an increased rate of urea nitrogen transfer from the circulation to the intestine, as suggested by Younes et al. ${ }^{46}$

Currently the standard treatment of portosystemic encephalopathy is $100 \mathrm{~g}$ lactulose/ day, or roughly $160 \mathrm{~g} / \mathrm{kg}$ dry food. ${ }^{43}$ In western societies, the average dietary calcium intake is about $1 \mathrm{~g} /$ day, or roughly $40 \mathrm{mmol} / \mathrm{kg}$ dry food. The rat diets of the present study contained $100 \mathrm{~g}$ lactulose $/ \mathrm{kg}$ dry food and 20 (low calcium) or $180 \mathrm{mmol}$ calcium $/ \mathrm{kg}$ dry food (high calcium). Although a direct extrapolation of the results from the present rat study to the human situation is inappropriate, the relatively high dose of lactulose prescribed to humans and their relatively low dietary calcium intake warrants serious concern about the balance between these food ingredients in humans.

In conclusion, the present study shows that dietary calcium phosphate and lactulose are additive in improving the resistance to intestinal infection. The combination of lactulose and an ample dietary calcium supply not only increased the colonisation resistance, but also reduced translocation of $S$ enteritidis to the systemic circulation. This beneficial effect is probably mediated by increasing the buffering capacity of intestinal contents and decreasing the cytotoxicity of faecal water by precipitating surface active bile acids, which reduces damage to epithelial cells. Considering the high dose of lactulose prescribed in certain clinical situations and the current keen interest in health foods containing fermentable fibre or oligosaccharides, the dietary supply of calcium phosphate must be adapted to control intensive, acidic fermentation and to prevent damage to the intestinal mucosa. 

We thank Michiel Sno (Solvay Duphar, Weesp, The
Netherlands) for kindly providing lactulose, Mischa Wissink, Henk Klomp, Jan Leenders, and Roelie Holleman for assistance with analysis, Maria Faassen-Peters for taking care of the animals, and Anton Weerkamp for stimulating discussions.

1 Bircher J, Muller J, Guggenheim P, Haemmerli UP. Treatment of chronic portal-systemic encephalopathy with lactulose. Lancet 1966; i: 890-3.

2 Conn HO, Lieberthal MM. The hepatic coma syndromes and lactulose. Baltimore: Williams and Wilkins, 1979.

3 Liao W, Cui XS, Jin XY, Florén CH. Lactulose - a potential drug for the treatment of inflammatory bowel disease. Med Hypotheses 1994; 43: 234-8.

4 Hanssen HB, Barkenius G, Cronberg S, Jutlin I. Controlled comparison of nalidixic acid or lactulose with placebo in Shigellosis. Scand I Infect Dis 1981; 13: 191-3.

5 Hoffman K. Treatment of healthy Salmonella carriers with lactulose ( $\beta$-galactosido-fructose). Dtsch Med Wochenschr 1975; 100: 1429-31

6 Gardiner KR, Erwin PJ, Anderson NH, McCaigue MD, Halliday MI, Rowlands BJ. Lactulose as an antiendotoxin in experimental colitis. $\operatorname{Br} \mathcal{f}$ Surg 1995; 82: 469-72.

7 Pell JD, Johnson IT, Goodlad RA. The effects of and interactions between fermentable dietary fiber and lipid in germfree and conventional mice. Gastroenterology 1995; 108: $1745-52$.

8 Argenzio RA, Meuten DJ. Short-chain fatty acids induce reversible injury of porcine colon. Dig Dis Sci 1991; 36: 1459-68.

9 Rémésy C, Levrat MA, Gamet L, Demigné C. Cecal fermentations in rats fed oligosaccharides (inulin) are
modulated by dietary calcium level. Am 7 Physiol 1993; 264: G855-62.

10 Govers MJAP, Van der Meer R. Effects of dietary calcium and phosphate on the intestinal interactions between calcium, phosphate, fatty acids, and bile acids. Gut 1993; 34: 365-70.

11 Bovee-OudenhovenI, Termont D, Dekker R, Van der Meer R. Calcium in milk and fermentation by yoghurt bacteria increase the resistance of rats to Salmonella infection. Gut 1996; 38: 59-65.

12 Govers MJAP, Termont DSML, Van der Meer R. The mechanism of the antiproliferative effect of milk mineral mechanism of the antiproliferative effect of milk mineral
and other calcium supplements on colonic epithelium. Cancer Res 1994; 54: 95-100.

13 Rampling A. Salmonella enteritidis five years on. Lancet 1993; 342: 317-8.

14 Lacey RW. Food-borne bacterial infections. Parasitology 1993; 107: S75-93.

15 Oudenhoven IMJ, Klaasen HLBM,Lapré JA, WeerkampAH, Van der Meer R. Nitric oxide-derived urinary nitrate as a marker of intestinal bacterial translocation in rats. Gastroenterology 1994; 107: 47-53.

16 American Institute of Nutrition. Report of the American Institute of Nutrition ad hoc committee on standards for nutritional studies. F Nutr 1977; 107: 1340-8.

17 Fiske $\mathrm{CH}$, Subbarow Y. The colorimetric determination of phosphorus. F Biol Chem 1925; 66: 375-400.

18 Giaffer MH, Holdsworth CD, Duerden BI. The assessment of faecal flora in patients with inflammatory bowel disease by a simplified bacteriological technique. $\mathcal{F}$ Med Microbiol 1991; 35: 238-43.

19 Green LC, WagnerDA, GlogowskiJ, SkipperPL, WishnokJS, Tannenbaum SR. Analysis of nitrate, nitrite, and $\left[{ }^{15} \mathrm{~N}\right]$ nitrate in biological fluids. Anal Biochem 1982; 126: 131-8.

20 International Dairy Federation. Determination of lactulose content. International Dairy Federation International Standard 147: 1990.

21 Koops J, Klomp H, Elgersma RHC. Rapid determination of nitrogen in milk and dairy products by colorimetric estimation of ammonia following an accelerated digestion procedure. Netherlands Milk and Dairy fournal 1975; 29: procedure.

22 Crowther RS, Wetmore RF. Fluorimetric assay of O-linked glycoproteins by reaction with 2-cyanoacetamide. Anal Biochem 1987; 163: 170-4.

23 Van der Meer R, De Vries HT, Glatz JFC. t-Butanol extraction of feces: a rapid procedure for enzymatic determination of fecal bile acids. In: Beynen AC, Geelen MJH, Katan MB, Schouten JA, eds. Cholesterol metabolism in health and disease. Wageningen: Ponsen and
Looyen, 1985: 113-9.
24 Mashige F, Imai $K$, Osuga T. A simple and sensitive assay of total serum bile acids. Clin Chim Acta 1976; 70: of total

25 Lapré JA, Termont DSML, Groen AK, Van der Meer R. Lytic effects of mixed micelles of fatty acids and bile acids. Am F Physiol 1992; 263: G333-7.

26 Florent C, Flourie B, LeBlond A, Rautureau M, Bernier JJ, Rambaud JC. Influence of chronic lactulose ingestion on the colonic metabolism of lactulose in man (an in vivo study). $\mathcal{F}$ Clin Invest 1985; 75: 608-13.

27 Moncada S, Palmer RMJ, Higgs EA. Nitric oxide: physiology, pathophysiology, and pharmacology. Pharmacol Rev 1991; 43: 109-42.

28 Gianotti L, Alexander JW, Pyles T, Fukushima R. Argininesupplemented diets improve survival in gut-derived sepsis and peritonitis by modulating bacterial clearance. Ann and peritonitis by modulat

29 Carter PB, Collins FM. The route of enteric infection in normal mice. f Exp Med 1974; 139: 1189-203.

30 Clark MA, Jepson MA, Simmons NL, Hirst BH. Preferential interaction of Salmonella typhimurium with mouse Peyer's patch M cells. Res Microbiol 1994; 145: 543-52.

31 Drasar BS. The bacterial flora of the intestine. In: Rowland IR, ed. Role of the gut flora in toxicity and cancer. London: Academic Press, 1988: 23-38.

32 Heijnen AM, Brink EJ, Lemmens AG, Beynen AC. Ileal pH and apparent absorption of magnesium in rats fed on diets containing either lactose or lactulose. Br $₹$ Nutr 1993; 70: 747-56.

33 Mital BK, Garg SK. Anticarcinogenic, hypocholesterolemic, and antagonistic activities of Lactobacillus acidophilus. Crit Rev Microbiol 1995; 21: 175-214.

34 Link-Amster $\mathrm{H}$, Rochat $\mathrm{F}$, Saudan KY, Mignot $O$, Aeschlimann JM. Modulation of a specific humoral immune response and changes in intestinal flora mediated through fermented milk intake. FEMS Immunol Med Microbiol 1994; 10: 55-64

35 Sahota SS, Bramley PM, Menzies IS. The fermentation of lactulose by colonic bacteria. Fournal of General Microbiology 1982; 128: 319-25.

36 Mouricout M, Petit JM, Carias JR, Julien R. Glycoprotein glycans that inhibit adhesion of Escherichia coli mediated by K99 fimbriae: treatment of experimental colibacillosis. Infect Immun 1990; 58: 98-106.

37 Mantle M, Thakore E, Hardin J, Gall DG. Effect of Yersinia enterocolitica on intestinal mucin secretion. Am $\mathcal{F}$ Physiol 1989; 256: G319-27.

38 Hedger RW, Ing TS, Wang F, Kovithavongs T. Lactulose therapy in chronic renal failure. $\mathcal{F}$ Lab Clin Med 1971; 78: 1015A.

39 Lim EC, Rubulis A, Faloon WW. Effect of lactulose upon intestinal absorption. Gastroenterology 1971; 60: 782A.

40 Gorden J, Small PLC. Acid resistance in enteric bacteria. Infect Immun 1993; 61: 364-7.

41 Govers MJAP, Termont DSML, Van Aken GA, Van der Meer $\mathbf{R}$. Characterization of the adsorption of conjugated and unconjugated bile acids to insoluble, amorphous calcium phosphate. $¥$ Lipid Res 1994; 35: 741-8.

42 Stohs SJ, Bagchi D. Oxidative mechanisms in the toxicity of metal ions. Free Rad Biol Med 1995; 18: 321-6.

43 Bird SP, Hewitt D, Ratcliffe B, Gurr MI. Effects of lactulose and lactitol on protein digestion and metabolism in conventional and germ free animal models: relevance of the results to their use in the treatment of portosystemic encephalopathy. Gut 1990; 31: 1403-6.

44 Mortensen PB. The effect of oral-administered lactulose on colonic nitrogen metabolism and excretion. Hepatology 1992; 16: 1350-6.

45 Bliss DZ, Stein TP, Schleifer CR, Settle RG Supplementation with gum arabic fiber increases fecal nitrogen excretion and lowers serum urea nitrogen concentration in chronic renal failure patients consuming a low-protein in chronic renal failure patients consu

46 Younes H, Demigné C, Behr S, Rémésy C. Resistant starch exerts a lowering effect on plasma urea by enhancing urea $\mathrm{N}$ transfer into the large intestine. Nutr Res 1995; 15: 1199-210.

47 Stephen AM, Cummings JH. The microbial contribution to human faecal mass. $\mathcal{Y}$ Med Microbiol 1980; 13: 45-56.

48 Freter R. Mechanisms that control the microflora in the large intestine. In: Hentges DJ, ed. Human intestinal microflora in health and disease. London: Academic Press, 1983: 33-54 